\title{
The impossibility of finitism: from SSK to ESK?
}

\author{
DAVID TYFIELD \\ Institute for Advanced Studies, Lancaster University
}

\begin{abstract}
The dramatic and ongoing changes in the funding of science have stimulated interest in an economics of scientific knowledge (ESK), which would investigate the effects of these changes on the scientific enterprise. Hands (1994) has previously explored the lessons for such an ESK from the existing precedent of the sociology of scientific knowledge (SSK). In particular, he examines the philosophical problems of SSK and those that any ESK in its image would face. This paper explores this argument further by contending that more recent literature in SSK exposes even deeper philosophical problems than those identified by Hands. Meaning finitism has emerged as the philosophical core of SSK. An examination of the profound problems with this position is used to show that an underlying extensionalism is the root of SSK's intractable philosophical difficulties, and to illustrate the entirely different approach of a critical philosophy that is advocated in its place. In this way, the project of an ESK is shown to depend upon a critical philosophy.
\end{abstract}

Keywords: economics of science, sociology of scientific knowledge (SSK), meaning finitism, extensionalism, critical philosophy

JEL Classification: B40, Z13

The dramatic changes currently occurring in the funding and economic imperatives of scientific research have naturally led to an upsurge in interest in an economics of science (e.g., Mirowski and Sent 2008; Mirowski and Sent 2002). Indeed, allied to a number of disciplinary developments in the philosophy of science and economics, recent years have seen the emergence of a plethora of research projects all calling themselves the 'economics of science' but with little in common beyond

AUTHOR'S NoTE: I would like to thank Francesco Guala, Uskali Mäki, the participants of the LSE Conference on Philosophy of Social Sciences 2005, and two anonymous referees, for comments on earlier drafts of this paper. Any errors that remain are, of course, mine. 
the name (Sent 1999). Few if any of such projects offer explanations of why these changes have occurred. Nor do they offer theoretical frameworks for rigorous examination of the effects of these changes on the production of scientific knowledge, what may be called an 'economics of scientific knowledge' (ESK). Such a research programme, however, seems to be of exceptional practical importance in an age characterized by the social penetration of, and dependence upon, scientific knowledge. Indeed, there have been widespread expressions of concern regarding the potentially corrosive effects of the deepening presence of economic incentives in scientific research. ${ }^{1}$ There is thus a significant gap calling for this ESK to be established.

As Hands (1994) notes, the sociology of scientific knowledge (SSK) seems to be an obvious place to start for such an ESK. Yet he points out that any SSK-based ESK would need to face up to the particular philosophical problems that beset SSK; in 1994, this was revolving primarily around the so-called "problem of reflexivity". However, much of recent debate regarding SSK (and particularly the strong programme of the Edinburgh School) has been concerned with the related issues of meaning "finitism", "interactionist" social ontology, and Kripke's Wittgenstein, marking a definite shift in the philosophical debate from earlier concerns about reflexivity. ${ }^{2}$ Indeed, finitism must now be acknowledged as a (or perhaps even the) central element of the model of science \& technology studies (STS) associated with the Edinburgh School.

Far from this shift in the debate leading to stronger philosophical grounds, it seems that SSK's philosophical problems are as deep as ever. It is argued here that the philosophical problems of SSK are much more profound than the familiar problems of "reflexivity". In particular, finitism is intelligible only if it is false. It follows that SSK is not merely self-refuting, but, insofar as it holds onto finitism, it is unintelligible. If SSK is even to be able to sustain its own research programme, let alone act as role model for an ESK, it must therefore forsake finitism.

\footnotetext{
${ }^{1}$ See, e.g., Boyle 1996, Boyle 2003; Brown 2000; Campbell, et al. 2002; Eisenberg 1987; Eisenberg 1996; Geiger 2004; Heller and Eisenberg 1998; Krimsky 2003; Nelson 2001; Nelson 2004; Newfield 2003; Resnik 2007; Washburn 2005; and references in Mirowski and Sent 2002. For more sanguine assessments of the changes see, e.g., Callon 2002; Greenberg 2001; Shapin 2003; Tijssen 2004.

${ }^{2}$ See, e.g., the debates between Kusch (2004), Bloor (2004), and Sharrock (2004); and between Stueber (2005, 2006), King (2006), and Bernasconi-Kohn (2006). For the purpose of brevity, unless otherwise stated I will be using 'SSK' to refer exclusively to the Edinburgh School in this paper.
} 
Analysis of this problem reveals the root of these philosophical woes to be SSK's implicit philosophical commitment to an "extensionalist" theory of meaning, in which (the development of) the meaning of a term is understood in terms of (the growth of) the set of objects incorporated under that label. Repudiation of this extensionalism demands taking a completely different approach to the philosophical examination of the nature (or ontology) of meaning. This novel approach is effectively "transcendental" or "critical" in nature, involving examination of the necessary conditions of possibility of the premise; in this case, the familiar but problematic possibility of intelligible application of meanings and rules. In short, in order to resolve SSK's philosophical problems so that it can fulfil its potential as an insightful examination of the social nature of scientific knowledge production and act as model for an ESK, the entire approach to the philosophical issues that plague SSK must be rethought.

The paper proceeds as follows. In the next section, I introduce SSK in more depth and explore the centrality of meaning finitism in its philosophical vision. In the following sections, I proceed to explore the philosophical problems with SSK, first reviewing the familiar problems already discussed in the ESK literature, and then turning to the deeper problems regarding meaning finitism and its underlying extensionalism. The latter argument is then developed in a discussion of the resolution of these problems offered by the alternative approach of a critical and transcendental philosophy, before concluding in the final section.

\section{WHAT IS SSK? THE CENTRALITY OF FINITISM}

In order to appraise SSK, we must first work out what it is. In brief, SSK is the empirical examination of the generation of scientific knowledge as an open-ended and contingent social process, situated in specific sociohistorical locations. ${ }^{3}$ As is often (always?) the case, one may perhaps understand its project more clearly by considering what it is against; in this case, that is: Parsonian functionalist sociology of norms; Mertonian sociology of science; and, underlying both of these, what Barnes and Bloor dub 'rationalist' ex ante philosophy of science. ${ }^{4}$

\footnotetext{
${ }^{3}$ The literature on SSK is now very large. For overviews, see Barnes and Edge 1982; Barnes, Bloor, and Henry 1996; Barnes 1974; Bloor 1991; Collins 1983; Shapin 1995, and references therein. On the 'social turn' in the philosophy of science more generally following Kuhn 1970; see Hands 2001, chapter 5.

${ }^{4}$ For a discussion of Parsons, see Barnes 1995. For the sociology of science, see Merton 1973. Barnes and Bloor use the term 'rationalist' philosophy of science, for example, in
} 
As such SSK is both a sociological enquiry into the actual generation of beliefs in the social world of 'science', and a naturalistic (if not antiphilosophical) philosophy of science upon which the former is based. ${ }^{5}$ The key move in the development of SSK is the shift from the investigation of science for the truth (or rationality) of scientific knowledge to the question of why belief A rather than B (or C, or...) is accorded credibility by the scientific community. ${ }^{6}$ The history of science reveals that the development of scientific knowledge is ridden with controversy. The 'facts' can be, and are, interpreted in many different ways. It follows that the 'facts' themselves cannot determine scientific knowledge. SSK instead turns its attention to the causal explanation of how different beliefs come to be believed. Given that all beliefs must come to be believed, this leads to the "symmetry principle", which demands that both 'true' and 'false' scientific beliefs must be treated equally as regards how people came to accept them (Barnes and Bloor 1982, 23).

How is this position reached? Starting from the Kuhnian insights into the social relativity of beliefs and the theory-ladenness of observation, and the broader changes in post-positivist (e.g., Quinean) philosophy towards a non-foundational epistemology, SSK argues that whether our beliefs are true or false is entirely inaccessible to us, for we cannot step outside ourselves and our social world in order to compare our beliefs with the world as it is. ${ }^{7}$ It follows that there is no ultimate appraisal of scientific knowledge, only the situating of it in further scientific understanding of how 'scientific' knowledge is produced and the status of that 'knowledge'.

Barnes and Bloor 1982. The phrase seems to include not only classical logical positivism of the "Received View" (Suppe 1977; Hands 2001) but also post-positivist developments that seek to uncover the rationality of the development of science. Thus Lakatos 1970; Laudan 1977; and Worrall 1990, are all explicitly cited as examples on various occasions. For an extended debate between the positions see Laudan 1981, 1982; and Bloor 1981.

${ }^{5}$ Classic examples of the former include Collins and Pinch 1993; and Shapin and Schaffer 1985. Note also that 'inductivist' in this context means simply that the logic of this process is ampliative and not only logically determined, as per deductive schemas of reasoning.

${ }^{6}$ There is a possible ambiguity in the term 'credibility', noted by Haddock $(2004,3,5)$. As I use the term, it refers to the actual social acceptance given to a belief and not the belief's plausibility.

${ }^{7}$ Barnes and Bloor explicitly refer to Quine $(1960,1980)$ much less often than to Wittgenstein. Nevertheless he is acknowledged as a major source of their work. See, e.g., Bloor 1998, 632; Barnes 1982; and Barnes 1983. 
Another way in to the argument proceeds from (a reading of) Wittgenstein's Philosophical investigations (2001). ${ }^{8}$ This starts from a position in which social life and interaction, including the development of (scientific) knowledge, is a matter of extending meanings, rules, and classes to new instances; a theoretical position called "extensionalism". Pickering $(1992,4)$ summarizes the resulting argument well:

Since the central problematic of SSK is that of knowledge, the first move is to characterize the technical culture of science as a single conceptual network, along the lines suggested by the philosopher of science Mary Hesse (1980). ${ }^{9}$ Concepts [...] within the net are said to be linked to one another by generalizations of varying degrees of certainty, and to the natural world by the piling up of instances under the headings of various observable terms. When scientific culture is specified in this way, an image of scientific practice follows: practice is the creative extension of the conceptual net to fit new circumstances. ${ }^{10}$

This process of extending the net to new instances, however, is not logically determined by the meaning (or rule, or class) itself. In the famous example deployed by Wittgenstein (2001, §185), for instance, a child is asked to "add" 1 to a particular number, in order to test their understanding of arithmetic. Instead of counting " $1,2,3,4 \ldots$ ", however, the child continues " $1,11,111,1111 \ldots$ " One may rebuke the child for not understanding, but in fact "plus", or any other term, cannot be exhaustively and unambiguously defined so as to make its application always certain and uniquely logically determined. Hence the chastened child may now simply proceed " $1,2,3,4,11,12,13 \ldots$ " instead and may continue to offer unexpected variations that fit the further specified and refined requirements of the rule ad infinitum.

\footnotetext{
${ }^{8}$ The validity of this reading is the subject of much of the recent debate. See, for example, the exchange between Bloor (1992) and Lynch (1992a, 1992b), as well as more recent work by Kusch $(2004,2006)$, with replies from Bloor (2004) and Sharrock (2004). Perhaps it would be more accurate to use the common neologism of 'Kripkenstein' rather than Wittgenstein when referring to SSK's philosophical influences, following Kripke's (1982) exposition of Wittgenstein, though even this differs in important respects from SSK's argument. More on this below, but also see Bloor 1997.

${ }^{9}$ For 'Hesse nets' see also Hesse 1976.

${ }^{10}$ Note that the two communities party to this debate, philosophers and sociologists, tend to use the term 'extension' in two slightly different ways. For philosophers, the 'extension' is the extent of the particulars covered by that class. For sociologists (e.g., Pickering 1992, 4) 'extension' refers to the act of extending this class to the next instance. I will be using the term in the philosophical sense.
} 
In short, logical determination of the application of rules cannot reside in the rules themselves, but can only be determined for all instances where they are themselves already specified. As such, an infinitely specified definition is impossible, the resulting theory of meaning is "finitism", so-called because at any one time the existing extension of a meaning is finite, and it is precisely because of this that extending it to the next instance is not already determined. According to Barnes, et al. (1996), finitism may therefore be defined by five criteria, namely:

1) Future applications of terms are open-ended;

2) No act of classification is ever indefeasibly correct;

3) All acts of classification are revisable;

4) Successive applications of a kind term are not independent; and

5) The applications of different kind terms are not independent of each other.

In short, this presents an inductivist account such that:

a class is its accepted instances at a given point of time: those instances are the existing resources for deciding what else belongs in the class, the available precedents for further acts of classification, the basis for further case-to-case development of classification (Barnes, et al. 1996, 105). ${ }^{11}$

This argument is generally used to argue that, in the absence of determination of future applications by existing meanings, there is no (private, mentalistic) fact of the matter regarding what is meant by a proposition; what may be called "meaning scepticism".

In the case of SSK, however, the particular application of this argument regards the process of science, with such a model taken to represent the development of all scientific knowledge. This leads to the conclusion that 'philosophy', which attempts to explain how the development of science is a rational process determined by the internal logic of scientific knowledge, is entirely wrong-headed, attempting the impossible. Nor does SSK shy away from the radical implications of this thesis. Thus it is argued that logic itself cannot be deductively, i.e., logically, justified; for the meaning of the logical operations themselves

\footnotetext{
${ }^{11}$ See also Barnes and Bloor 1982, 39.
} 
are classifications whose extension is also open-ended. ${ }^{12}$ It follows that, pace 'rationalist' philosophy of science, neither logic nor the empirical evidence determines the development of science.

If this is the case, it follows that something else must determine what scientists believe and how these beliefs change. SSK's solution is that social interests are the relevant determining factor and thus social science can explain the development of science more generally (Barnes 1982, 35; Barnes, et al. 1996, 29). A strict dichotomy is thus set up between investigating the process of science philosophically (wrong, according to SSK) and sociologically (right). As Mäki (1992) claims, this is a radically pro-science, even scientistic programme, in which science is to be explained by more science, and there is never deemed to be any need for philosophical justification. ${ }^{13}$

In order to be able to examine the empirical and contingent process of knowledge production as a social process, SSK also needs a social ontology that can make sense of the contact between social factors and the production of science, thus conceived. This takes us to the second element of SSK's argument-set against Parsonian functionalismnamely the social ontology of "interactionism", so named because social 'reality' is argued to be the outcome of the concrete interactions of actual (sociable and mutually-susceptible) individuals.

Interactionism is effectively a social ontology of finitist social rules. It acknowledges the experience of apparently irreducible social facts, particularly as social rules and norms, and so rejects methodological individualism. But these social rules are not accorded ontological status as 'real', and so reified as in Parsonian functionalism, because the apparent intransigence of society is simply the result of taking too narrow a perspective (King 1999a, 1999b, 2006).

Clearly, social rules are meaningful or else they could not be followed (nor transgressed) by human agents. However, given the picture of meaning discussed above, the application of a social rule in any given instance is precisely to extend a rule so as to include a new particular. Finitism shows, though, that the pre-existing meaning of the social rule cannot logically determine this process. It follows that social

\footnotetext{
${ }^{12}$ See Barnes, et al. 1996, 198, et seq., for consideration of the paradox of the heap as the reductio ad absurdum of modus ponens; also see Barnes and Bloor 1982, 42.

${ }^{13}$ Barnes $(1982,38)$ calls SSK a "totally naturalistic approach to semantic problems". Hands $(1997,2001)$ also argues that SSK is simply a philosophical naturalism, like those deferring to biology or cognitive science.
} 
rules cannot determine-nor therefore explain-any apparent 'following' of the rule nor any other associated social process.

For interactionism, therefore, social rules are merely the finitist precedent produced by past concrete interactions of individuals. The resulting social ontology is 'interactionist' in that it consists of the output of the negotiations and consensus of all the interactions of humanity throughout history regarding the extension, and hence meaning, of 'social rules', i.e., a conception of 'Social life as bootstrapped induction' (Barnes 1983). From the perspective of any one individual, therefore, social reality will seem given and real, but in fact this is simply because the social 'reality' confronting us is the result of the interactions of all the rest of humanity, which are obviously always greatly beyond our individual control.

Taking these two strands of analysis of science and social ontology together, then, what is the effect of this argument as regards SSK's empirical and sociological program for studying the interaction of science and society? If we acknowledge that both, social rules and scientific theoretical propositions, are meanings (part of the conceptual 'Hesse net') and that these are only extended 'inductively', it follows immediately that the very content of scientific knowledge will also be responsive (however indirectly) to the social positioning, and hence to the particular understanding associated with given social interests, of the scientists.

Furthermore, given that there is only ever comparison of beliefs within the net of meaning and so no discrimination of 'true' and 'false' beliefs by comparing them directly with the world, social factors can be seen to feature in explanations of all scientific knowledge and not just lapses or corruptions of the 'pure' logic of scientific discovery through reference to perversion of the specifically scientific social norms. It follows that, as regards the third and final limb of SSK, Mertonian sociology of science is seen to be wrong in the 'rationalist' assumption of a scientific method and its consequent exclusive focus on the social conditions necessary for the emergence of the particular social norms that characterize the institution of this disinterested scientific enquiry. ${ }^{14}$ For SSK, such sociology of science does not go far enough in its employment of sociological analysis in science, i.e., right into the heart

14 That is, the (in-?)famous four norms of 'Disinterestedness', 'Communism', 'Scepticism', and 'Universalism': see Merton 1973; and the discussion in Hands 2001, 180 , et seq. 
of scientific knowledge and not just concerning the institutional norms of 'science'.

In summary, in the context of massive changes to the economics of science, examination of the impact of economic conditions on the production of scientific knowledge-an economics of scientific knowledge (ESK)-would seem to be extremely important. SSK seems to afford the examination of the interaction of social beliefs and (the development of) scientific knowledge itself in just the way we are seeking for such an ESK. However, were we to consider an SSK-based ESK, we must immediately acknowledge the significant problems with SSK, to which we now turn.

\section{PROBLEMS WITH SSK 1: THE FAMILIAR PROBLEM OF REFLEXIVITY}

Probably the most high profile of SSK's theoretical problems is its perennial problem of reflexivity, as it has been discussed in earlier examinations of the suitability of SSK for ESK (Hands 1994). Indeed, "all of the authors involved in the recent SSK feel impelled to give some response to the question of reflexivity and the relativism (that many suggest) it implies" (Hands 1994, 93, original emphasis). Furthermore, "what tends to happen [in SSK studies] is that the sociological theories and (anti) philosophical arguments upstage" its empirical work (Hess 1997). But SSK's anti-philosophical naturalism is so domineering precisely because of the intractable philosophical and theoretical problems it throws up. If we are to resolve these problems and fulfil SSK's promise as an examination into the interaction of social factors and the production of knowledge, then we must pay some explicit attention to these philosophical problems and their origins.

What, though, is the problem of reflexivity? As Hands summarizes it:

Many of the advocates of the SSK claim to undermine the hegemony of the natural sciences by showing that what is purported to be objective and 'natural' is neither one of these things, but rather simply a product of the social context in which it is produced. If this is true for all human inquiry, then it must be said for the SSK as well; this makes everything socially/context dependent and thus relative. (Hands 1994, 92, original emphasis).

It follows that there would be no grounds, other than social happenstance, for accepting any belief, and this includes SSK itself. 
Hence the "problem of reflexivity" is that if the SSK argument is correct, we have no grounds to accept SSK itself.

I agree with this point (though it is made rather too quickly here, as we shall see), but I do not draw the same conclusions as Hands. For Hands $(1994,96)$ concludes that the problems of reflexivity of SSK are "not so great as to deter entry" into an economics of science in SSK's footsteps. Rather, he sees the experience of SSK as informative, offering cautionary tales about the 'wilderness' through which it has walked and for which economics of science must also steel itself (Hands 1994, 97).

But on what grounds can Hands counsel that reflexivity does not present such a problem for SSK so as to rule out economics of science $a b$ initio? For when Hands writes that: "Those involved in the SSK have travelled through much of this wilderness [of reflexivity problems and philosophical disorientation] before us, and to neglect their signposts would surely be a folly" (Hands 1994, 96), this can only be read so as to license a recommendation to follow them on the condition that SSK has actually travelled 'through' the wilderness and not merely 'into' it, i.e., it must have come out the other side. SSK's route must take us somewhere worth travelling to.

It is by no means clear to me that SSK is not, philosophically, still wondering adrift. Indeed, to be fair to Hands, his more recent writings on SSK and economics of science (Hands 1997, 2001) do not make such a bold claim as regards the 'role-model' SSK can provide, perhaps precisely because the intervening period has seen merely an exacerbation of this problem as parts of science \& technology studies take ever-more outlandish stances in an attempt to deal with it. Indeed, the relative philosophical conservatism of SSK is a major reason that I have chosen it in particular as the STS tradition addressed in this paper, with the philosophical critique being offered applying a fortiori to other, more radically anti-philosophical STS perspectives.

But it follows that if SSK is still stranded, then surely the best signpost to follow would not be those SSK has posted that lead nowhere, but the one that says 'Danger, Wilderness Ahead, Do Not Enter'. The only other alternative is that SSK is, like democracy according to Churchill, the worst option apart from all the others. Nonetheless, for this to be the case, two points must be established: (1) just how bad it is, for it may be that anything would be better, even the status quo; and (2) what the alternatives are, if there are any. In 
answering these questions, we will also see how the problem of reflexivity arises from the deeper problem of SSK's finitism.

Let us consider each of these points in turn. First, it may be retorted that this argument assumes that the wilderness is a particularly inhospitable place-that reflexivity presents a particularly devastating problem for SSK-and this is not the case. Certainly, this line of argument is perfectly defensible given one reading of the reflexivity problem. This states that the relevant criterion for assessment of scientific knowledge is its credibility, and that this is the case no matter whether the belief is in fact, coincidentally, 'true' or 'false'. SSK itself, therefore, must also be susceptible to this kind of reflexive investigation, which would show how social factors have influenced its acceptance by some groups and rejection by others. But this requires only that the credibility conferred to all beliefs, whether 'true' or 'false', demand social explanation, and this is not the same as claiming that there is no difference between 'true' and 'false' beliefs, which would lead to reflexivity being a problem.

Thus stated, it is quite right that the credibility of SSK is a social phenomenon and that this does not entail that accepting beliefs is merely a matter of whim. In this case, the reflexivity is a satisfying, not a negating, one. But then, we have been worrying about nothing! Reflexivity is not a problem at all. There is no wilderness ahead but civilization, science!

Unfortunately, this is clearly not the case, as a more in-depth consideration of SSK shows. To criticise SSK in this way demands particular caution if we are to give it a fair hearing. We have seen SSK's argument is in fact a radical repudiation of mainstream philosophy of science. It is thus no surprise that it has both generated much controversy, and that misinterpretations abound. For instance, it must be appreciated that SSK does not claim, pace some vociferous critics, that there are no such things as true or false beliefs; or that there is no way the world is, independent of our knowledge of it. It is only claiming that we cannot know (in the traditional sense of having justified belief) whether our beliefs are true or false, and so this cannot feature in any explanation of why a belief is held, hence the symmetry principle. We can have true or false beliefs but this is merely a matter of coincidental correspondence, and this correspondence, or lack thereof, is not accessible to us in any particular case and so cannot count as one of the causes of actual acceptance of that belief. 
Nevertheless, even if we are careful about avoiding a straw man, SSK's stance is highly problematic. For instance, consider the argument that there can be no conclusive appraisal of scientific truth, only the shifting allocation of credibility amongst different scientific belief, all within the finitist net of meaning and never by direct comparison of meaning and world. We cannot know whether our scientific beliefs are true or false and so we cannot refer to 'truth' or 'falsity' of beliefs: the terms become idle and superfluous. Yet if we cannot take account of truth or falsity, we have no grounds on which to discriminate ' $\mathrm{X}$ ' from 'not X', so that we can believe both. As such, the 'truth' and 'falsity' of our beliefs is a necessary condition of the possibility of rational judgement, and without judgement we fall prey to an all-consuming relativism that makes all beliefs equally 'defensible'.

In other words, if we cannot refer to 'truth' or 'falsity' (as per symmetry), we must forsake altogether all use of these concepts, and this includes tacit presupposition as well as explicit usage. But this rules out rational judgement and so abandons us to relativism. In the case of SSK, this relativism is simply displaced into social terms so that the social context 'decides' what is and what is not 'knowledge', now redefined as merely "that system of beliefs that a community collectively accepts as knowledge" (Bloor 1991, 3). SSK is thus neither more nor less 'sound' than any competing argument. Nor, crucially, can it provide 'reasons' at all, thus belying the pleas of Barnes $(1974,156)$ that, while not presentable in any particular argument, SSK is to be accepted because "this whole volume is crammed with proffered reasons why its main tenets should be accepted; its justification lies within itself." Such talk of 'justification' is simply ruled out for SSK.

It is crucial to recognize that what is being argued here is not that SSK is avowedly relativist in this way. ${ }^{15}$ Indeed, I have stressed above how SSK's view on truth is not to deny that beliefs do in fact have a truth-value, only that we cannot know it either way in any particular case. However, it is a necessary condition of the possibility of rational judgement that we can employ the concepts of truth and falsity in the way that the symmetry thesis prohibits. And symmetry follows ineluctably from finitism and the Hesse-net picture of meaning, because these entail that all beliefs are simply a matter of shifting the credibility accorded to definitions in "the creative [and undetermined] extension of

\footnotetext{
${ }^{15}$ It is in this sense that Hands's reconstruction of the reflexivity argument above could be said to be too quick.
} 
the conceptual net" (Pickering 1992, 4). The present argument, therefore, is rather that, regardless of whether SSK is explicitly judgementally relativist or not, its allegiance to finitism and the symmetry thesis commits it to this relativism. Hence no amount of express protest about its rejection of this position can prove the contrary, just as the sceptic, conversely, cannot but display his lack of scepticism once outside the classroom by always leaving the building through the front door and never through the second floor window (Bhaskar 1998).

Should evidence for this theory and practice inconsistency in SSK's program be needed, it is available in abundance. For instance, given that use of the concept 'truth' is a necessary condition of the possibility of a rational discourse, and given further that SSK is participating in such a rational discourse while simultaneously proscribing use of the concept 'truth', it follows immediately that there is an insoluble paradox at its very heart that can only play itself out in interminable fractiousness and disagreement. And this, of course, is exactly what has happened to the wider SSK programme, splintering into mutually incompatible subprogrammes at loggerheads in a lethal but never-ending game of 'epistemological chicken', in which protagonists are challenged to take ever greater risks in the explicit affirmation of such a self-refuting judgemental relativism (Collins and Yearley 1992a, 1992b; Woolgar 1992; Callon and Latour 1992). In short, it seems that SSK throws itself out with its own bathwater. ${ }^{16}$ If this is the case, not only do these philosophical problems effectively prevent SSK from sustaining its critical challenge to Received-View philosophy and sociology of science, but also any economics of science that would follow SSK's lead would be beset by exactly the same errors.

But-it can be retorted-you cannot blame SSK for this! For as SSK shows, even logic itself cannot be justified in a non-circular way and all SSK is doing is pointing this out; we cannot blame the messenger. In other words, the logical circularity of deductive logic itself shows reflexive inconsistency to be inevitable. This is the typical defence employed by SSK. Barnes $(1974,39)$ argues, for instance, that such reflexive inconsistency is merely "the appalling, unresolved difficulties of philosophy" which "do not", and by implication should not, "worry

\footnotetext{
${ }^{16}$ Hands $(1994,95)$ uses the phrase, but I note that he is not referring directly to SSK when he does so. See also Rosenberg 1985 for statements to the same effect; and Callon and Latour 1992 for the original joke about the 'Bath school', though from a radically different perspective.
} 
the layman". ${ }^{17}$ The tactic thus is to claim innocence by way of universal guilt or to point out that, like it or not, the wilderness is the only option, because it is everywhere. The position is not hopeless, however, according to SSK, because its general inductivism leads to a bootstrapping philosophy, where 'truth' is accorded as a mark of post hoc success.

While it is not clear that this offers sufficient defence, it does seem that if we concede SSK's critical points-viz. that meaning is not unique and fully determining so that even logical terms do not logically determine-then there is at least a shift of the burden of proof onto those who would like to claim that reflexive inconsistency is a problem for theories because it is a criterion that discriminates (between consistent, and so tenable, beliefs and those that are not), rather than a ubiquitous and insuperable condition of all discourse. Indeed, in the absence of any demonstration to the contrary, SSK has been able to withstand such criticism despite the manifest inconsistency of its position for the last two decades. I believe that the critical arguments SSK makes against its various 'rationalist' opponents are sound, so it seems the challenge is to show that there is a way out of SSK's problems.

This takes us to the second problem of evaluating the alternatives to SSK's wilderness. The rest of the paper seeks to argue not only that there is such an alternative, but also that we can find it by looking at SSK itself, though not at what it would point out to us explicitly. Indeed, in order to see the alternatives what is needed is not some miraculous philosophical deus ex machina but a closer examination of the philosophical problems that are central to SSK's project, namely those associated with finitism: the theory of meaning that is pivotal in its conception of the interaction of science and society and that lies at the root of these intractable difficulties. What is needed is to conduct a transcendental philosophical examination of SSK's philosophical problematic itself. As we shall see, however, SSK's philosophical naturalism acts to preclude any such examination on its own part, and thus serves to prevent SSK from addressing, let alone resolving, its problems of reflexivity.

\footnotetext{
${ }^{17}$ Nor, it seems, the social scientist. Similarly, Collins, and Yearley (1992a, 308) argue that we all, not just SSK, find ourselves in an epistemic state of "permanent insecurity". See also Barnes and Bloor 1982, 41; and Bloor 1998, 629. The problem with such statements is not that they are wrong but, like all such sceptical positions, that they are hugely overstated.
} 


\section{PROBLEMS OF SSK 2: THE NOVEL PROBLEMS OF EXTENSIONALISM}

Let us, therefore, take a closer look at finitism. SSK sets itself against the thesis that the development of science is determined by the meanings of the propositions formulating the proto-scientific laws to be tested by empirical observation. Against this thesis, it argues that because scientific laws can be interpreted in numerous ways, they do not have unique meaning regarding their application or testing in any given case. Instead, SSK argues positively, the infinite number of extensions logically compatible with the existing set shows that the development of scientific knowledge is unconstrained by the meaning of the protoscientific laws, which merely act as 'precedents' facilitating any subsequent inductive determination of its extension.

The argument against 'rationalist' philosophy of science is cogent, but the derivative positive conclusion of finitism simply does not follow. That there is not one unique determinate meaning to any given proposition or rule does not entail that it can mean anything, but that it has many meanings, and 'many' does not equal 'any'. ${ }^{18}$ For SSK to be persuasive here, we must overlook this step, or be presupposing something that acts as a minor premise to validate the inference, by justifying the false dilemma of theories, rules, and the like, either having a unique meaning or meaning anything at all.

Similarly, consider the argument regarding social ontology and rules. The argument for finitism establishes that norms and rules cannot be formulated with sufficient precision to obviate the possibility of their systematic 'misunderstanding', giving them a logically consistent but alternative interpretation to that which is commonly socially accepted. Given that Parsonian norms are supposed to be such clearly-formulated and sui generis rules, it is plain that these could not possibly determine our social interaction in the way Parsons claims. Once again: so far so

\footnotetext{
${ }^{18}$ Compare to comments by Mermin $(1998,610)$ that: SSK's stretching of the related point of the underdetermination of theory by evidence to its radical conclusions overlooks the fact that it is "a trivial logical point [that] almost entirely misses the actual character of scientific practice." For "the problem confronting physicists [...] is rarely an overabundance of plausible theories [but...] is to find even a single reasonable theoretical structure [...]" (original emphasis). Bloor's (1998) response to this is particularly revealing for its characteristic shifting of meaning that conceals disagreement as agreement: "The problem is not that lots of theories fit perfectly: it is that nothing ever works properly [...] so why do we prefer this imperfection to that imperfection?" This entirely distorts Mermin's point, however, for he has not said that "nothing" ever works but that it is difficult, if possible, to find something that does. See also Laudan 1998; and Hacking 1992, 55.
} 
good. But once again, SSK presents a false dilemma of either rules determining social interaction or social interaction determining rules to derive the latter as its positive conclusion.

Given that these positive claims are finitist conclusions, therefore, we can conclude that finitism is ungrounded, the arguments in its favour resting on false dilemmas. Furthermore, once we dispense with finitism, the problems of reflexivity and relativism do not arise, because in each case these hang on SSK's positive claims, not its critical ones. Thus, for instance, it is the finitist argument regarding 'rationalist' philosophy of science, and the specifically finitist picture of meaning as extending 'Hesse nets' to new instances, that leads to ruinous relativism, as we have seen. But why does SSK consider finitism and the false dilemmas that justify it to be compelling? The answer to this question lies in SSK's extensionalist theory of meaning, on which its entire problematic is built. ${ }^{19}$

We can readily accept that extending rules/theories to the next instance is not logically determined by their existing extensions. But this only licenses finitism if the development of rules/theories is identified with this process of extending extensive sets, i.e., given extensionalism. Nevertheless, from this extensional theory of meaning and its development, it follows that the only conceivable form of determination is logical determination, which is binary: in a given case either there is logical determination or there is not, as when an argument is deductively valid or not.

Thus it is clearly extensionalism that licenses the false dilemma of uniquely determining or wholly indeterminate meaning; of meaning either one thing or anything/nothing. For given that the determination of the development of meaning is logical determination, the existing meaning (i.e., extensive set) determines how it is developed either uniquely or not at all. With 'meaning', 'development', and 'determination' thus defined (as 'extension', 'extending', and 'logical

\footnotetext{
${ }^{19}$ Ironically, Barnes (1982) explicitly contrasts finitism and extensionalism, and affirms that "an alternative to extensional semantics is essential" (Barnes 1982, 24). However, the question he then goes on to address is "what determines whether or not a concept properly applies to its next instance?" The terms of his analysis of meaning are thus explicitly extensionalist, for it is extensionalism alone that sets this as the relevant question regarding semantic issues. Barnes, et al. $(1996,105)$ also explicitly state that "a class is its accepted instances at a given point of time." It follows that Barnes's whole investigation is conducted within an extensionalist paradigm, even if his conclusions are not aligned with the main protagonists in the 'extensionalist' philosophical debate (e.g., Putnam as 'realist', and Searle as 'description theorist' in this case).
} 
determination' respectively), it follows also that meaning does not determine its own development at all, i.e., finitism. But notice that SSK has not concluded that there is no such thing as intrinsic meaning, for its non-existence is assumed in the extensionalism of the very formulation of the question it addresses.

Therefore, it is SSK's prior commitment to extensionalism, what underlies the false dilemmas that would justify their positive conclusions. Extensionalism, however, is a common philosophical position that, in SSK's useful terms, is accorded much credibility by the social community called 'philosophy'. The question is thus: why must it be discarded?

\section{TOWARDS AN ALTERNATIVE PHILOSOPHICAL APPROACH}

The first point to note in response to this question is that extensionalism is responsible for the positive claims of SSK and, as we have seen, these are blighted with an inimical relativism that renders them insupportable and self-refuting. ${ }^{20}$ Conversely, were we to dispense with extensionalism, we can retain the valuable critical arguments of SSK without being forced by the false dilemma to take that next step; one that then leads to the extinction of their critical challenge. This surely provides at least prima facie evidence, as a negative argument, to challenge extensionalism.

But positive arguments in favour of taking intensionality seriously are also easily marshalled. For, in each case, the intelligibility of SSK's claims rests on an unchallenged ambiguity that allows the tacit presupposition of what it is expressly denying to go unnoticed. In other words, it is not merely the case that SSK refutes itself but also that its positive claims, if true, would be unintelligible. It follows that if we understand the claims, they must be wrong.

Consider the Wittgensteinian (2001, §185) example of the ' +1 ' rule, discussed above. SSK argues that extending the rule, and its extension at any given point in time, is not logically determined; no formulation of the rule can ever be sufficiently precise that it rules out all interpretations but one (the one intended). Thus ' +1 ', and every other rule, is actually indeterminate; anything goes (e.g., Barnes, et al. 1996).

${ }^{20}$ There are legion other examples of direct inconsistency in SSK's pronouncements, e.g., regarding finitism and consistency see Barnes 1982, 38, where finitism is argued to be the result of consistency; and the various Barnes and Bloor quotations noted above at footnote 17 regarding the impossibility of consistency given finitism. Laudan $(1998,321)$ also notes the blithe inconsistency of SSK. 
But if such a rule can mean anything at all-if it can mean 'punch the teacher' or 'make porridge' or anything else at all-then it is utterly without content and so is totally unintelligible. Alternatively, we can see that we can only understand the point being made by the ' +1 ' example because we do understand the rule in a determinate way and are struck by the possibility of understanding in a different way. But this is miles away from saying that the rule has no determinate meaning at all, in which case it would be totally unintelligible, as would any statement about it including SSK's argument itself.

Thus consider, for instance, trying to make SSK's finitist point using the nonsense example 'trung tring' instead of ' +1 '. I say 'trung tring' to the difficult child and he proceeds to stand on his chair, or cry, or leave the room, or stare at me blankly, or else. Clearly, the finitist philosophical point cannot be demonstrated by this example because we do not already have some idea of what the rule means against which to compare the supposedly unusual interpretation of the child. Nor, therefore, can we say anything about this rule unless and until it does have some meaning for us. In other words, if ' +1 ' means anything at all, then SSK cannot intelligibly make any argument about it or making use of it. The only possible conclusion is that the extensionalist picture on which this argument is based is not what is happening in meaning use. As such, we can show that it is a necessary condition of the possibility of rule or meaning use that these are not, at any given time, totally unlimited in application.

Exactly the same criticism may be made of SSK's argument that the rules or theories underdetermine the development of scientific beliefs, which leads to the conclusion that social factors, such as interests, are the determining factor. But what are these social factors? According to the social ontology of SSK itself they can be no more than other social rules (e.g., the rule 'make money' or 'find a partner') 'known' by the individual, but these cannot, ex hypothesi, determine the social interaction that extends the other social rule. It follows that on SSK's model, there is no determinate connection between social interaction and social rules, in which case it seems misleading to argue that there are any social rules in the first place. Conversely, their conclusion is only plausible if social rules are intelligible, in which case they do have intrinsic, determinate content, i.e., they are intensional and not just extensional. 
A perfect illustration of this (which is also particularly relevant to issues of an ESK) is presented in Barnes et al. (1996) in discussion of a court case concerning a patent for aniline dyes. ${ }^{21}$ It is argued that what decides the outcome of the patent case is not the result of balancing of arguments, the "weighing" of "weightless quantities", but is "a consequence of the balance of power", i.e., as a matter of which decision will best serve the interests of the constitutional order and/or the legal establishment itself (it is not specified which). This sounds terribly scandalous, and of course it is welcome to remind us that a totally 'disinterested' judiciary is just nonsense, but on SSK's account, when there is nothing in the arguments made before the court that determines the outcome, we cannot even distort the decision by seeing how it would interact with 'our' or other power-political interests. Nor is there even any point in a judicial decision, because how the decision itself is then interpreted, whether in its implementation or in its future use as jurisprudential precedent, is entirely undetermined. Note that this also immediately makes a mockery of criteria 4 and 5 of finitism (mentioned above) that finitist meaning functions like a system of precedent, because finitism actually deprives such a system of any material that could ever act as such: precedents must constrain as well as enable; yet finitism systematically denies the former.

Similarly, unable to see any implications of 'knowing' that we have particular 'interests'-for there are none-then all decisions become impossible, as, ironically, Barnes et al. $(1996,124)$ themselves notice. In short, SSK cannot argue simultaneously that rules underdetermine and that the deficit is made up by other rules, yet its plausibility trades on this systematic ambiguity. SSK therefore argues that it can explain how scientists, judges, and the rest of us choose between belief A and belief $\mathrm{B}$, but overlooks the fact that it cannot explain how we can choose at all, because, in its repudiation of philosophy and ontology, it denies the material cause of a relatively autonomous intensional meaning upon which all such agency depends.

Similar arguments can be presented for all of SSK's positive finitist claims because in each case close reading shows that SSK is arguing as follows:

\footnotetext{
${ }^{21}$ Note also that, as presented, the argument suggests that the court is deciding on the actual chemistry and not merely on the patent dispute. It seems that Mermin (1998) also notices this.
} 
(1) not A (critique of 'rationalism', compatible with extensionalism but also with intensionality)

(2) either $A$ or $B$ (the disjunction of the false dilemma, from extensionalism)

Therefore

(3) $B$ (unintelligible if true, intelligible only if false)

Thus if we are to be able to understand SSK's claims at all, we must admit from the outset that rules do have determinate content that constrains (as well as enables), but does not itself fully determine, our subsequent action, including development of the rule itself. This yields the distinction between determinate (i.e., a material cause that is constraining in the instant, but transformable in the future) and (fully, uniquely) determining meaning..$^{22}$ But this is just to admit an intensional theory of meaning that acknowledges internal relations of necessity between different meanings, hence rendering meaning relatively resistant to our use of it so that we cannot simply do as we please-even collectively-with meaning, pace SSK. And this, in turn, is to refuse to identify meaning with extensive classes and extending them to new instances.

We have, therefore, repudiated the extensionalist theory of meaning that is the root of SSK's philosophical problems. In order to take this step, though, we have had to employ a transcendental, i.e., a specifically philosophical, argument, examining the necessary conditions of intelligibility of the philosophical problem itself. Such a sui generis philosophical analysis is exactly what SSK repudiates in its philosophical naturalism. However, this step is necessary for SSK if it is not to be forced to choose sides on the false dilemmas that arise from its philosophical neglect, in each case forcing SSK into a self-refuting position as we have seen. Thus SSK sees only that if extensionalism is right, then it is wrong, but sees it as inevitable, because it does not see that intensionality is presupposed anyway so that extensionalism is simply wrong: the initial premise is false and the argument collapses. Conversely, if we employ a transcendental approach as opposed to one

\footnotetext{
${ }^{22}$ Note also that, because meanings do not themselves fully determine, they also do not have agency, just as SSK correctly claims in its criticism of its various opponents. Instead, agency is reserved to human meaning-users in whom meaning resides, but here agency amounts to changing and not creating meanings (Bloor 1997, 70). There must be meanings in the first place or there is no possibility of an agent having any understanding, which in turn rules out agency, including the agency to manipulate and create new meanings.
} 
starting from the presumption of an extensionalist model of meaning, we can readily admit the intensionality of meaning and thus secure each of SSK's critical points, while (in the schema above) the step to B or conclusion (3), via the false dilemmas and ambiguities of premise (2), and the insoluble paradoxes that come with that step are avoided.

The refutation of premise (2) by transcendental reasoning, however, demands first that we admit the problems of finitism, for this alone can provide the motivation actually to examine the philosophical problems and not merely rest on an anti-philosophical complacency characteristic of naturalist perspectives. That is to say, so long as finitism is accepted one cannot even consent to the problems of reflexivity to be problems. For the 'net of meaning' picture makes it evidently absurd to attempt to step outside or beyond the net. Thus it is finitism, and the interactionist social ontology it sponsors, that licences the conflation of knowledge and social structure to the single un-tethered level of the net of meaning, and it is on this basis that problems of reflexivity are simply accepted as irresolvable. In the context of an underlying philosophical naturalism that precludes the analysis offered here and the admission of the importance of tackling philosophical problems, it follows that in order to begin even to address these problems, finitism must first be rejected.

The fundamental false dilemma underlying SSK is, therefore, that between first or ex ante 'rationalist' philosophy and naturalist or sceptical anti-philosophy. Taking its stand against the former, SSK immediately sides with the latter, but thereby finds itself cast into the fogs of relativism, which it then fully embraces in its defiant dismissal of the problems of reflexivity. It is SSK's (anti-) philosophical naturalism that explains the ex ante and unquestioned acceptance of extensionalism responsible for its intractable theoretical difficulties; thereby also explaining why SSK, despite its anti-philosophism, paradoxically finds itself dominated by its philosophical dimension, as noted by Hess above. But SSK need not take this option of philosophical naturalism because there exists the third option of a critical philosophical perspective, which asks [regarding rules/meaning]: given that [meaning use] is possible (at the price of ruling oneself into dumb silence), what is ontologically presupposed by this? With the clear alternative of a critical philosophy, then, we see that this element of SSK's program can, and indeed must, be relinquished. 


\section{CONCLUSION}

We have investigated SSK and concluded that, as it stands, it does not afford a profitable basis for the development of an ESK, but rather forecloses such a project. Furthermore, we have found this to be caused by the inadequate philosophical understanding at its heart: its extensionalist theory of meaning, which manifests in the problems of reflexivity and meaning scepticism. Confronting this problem forces us to take an entirely different approach, examining the ontological presuppositions of this impossible but apparently ineluctable challenge. This thereby repudiates the fundamental philosophical problematic from which extensionalism itself arises, namely the attempt to provide a watertight philosophical 'solution' to the problems of meaning use that arise when it is treated in terms of logical determination of the application of labels of extensive sets.

Such explicit transcendental philosophical examination, however, also significantly reorganizes the project of a social study of science, without thereby sacrificing its significant critical advantages over alternative research projects; which leave scientific knowledge sealed off, pristine, and inviolable for a wholly separate philosophy of science. Indeed, the exact opposite is the case: it is SSK itself that cannot sustain these critical points because, deprived of any possibility of knowing whether beliefs are true and even of any determinate meaning, it must rule itself into silence, taking even its own arguments with it. Time and again SSK points to important truths but on each occasion it then goes on to snatch them away, denying there are any truths at all.

The implications of such a reorientation of SSK are of central importance for any project of an economics of scientific knowledge. This is not only in the sense of offering a model that is itself not riddled with problems, but also because an ESK, if it is to do anything at all, must be able to offer a critique of how and where the imposition of economic imperatives on scientific research has a detrimental effect on the "scientific knowledge" thereby produced. In the age of the ubiquitous penetration of such economic issues into research, the failure, or rather refusal, of any SSK-inspired ESK to make such judgements would be a grievous loss to social criticism. 


\section{REFERENCES}

Barnes, S. Barry. 1974. Scientific knowledge and social theory. London: Routledge and Kegan Paul.

Barnes, S. Barry. 1982. On the extensions of concepts and the growth of knowledge. Sociological Review, 30 (1): 23-44.

Barnes, S. Barry. 1983. Social life as bootstrapped induction. Sociology, 17 (4): 524-545.

Barnes, S. Barry. 1995. The elements of social theory. London: UCL Press.

Barnes, S. Barry, and David Bloor. 1982. Relativism, rationalism and the sociology of knowledge. In Rationality and relativism, eds. Martin Hollis, and Steven Lukes. Oxford: Blackwell, 21-47.

Barnes, S. Barry, David Bloor, and John Henry. 1996. Sociology of scientific knowledge. London: Athlone Press; Chicago: University of Chicago Press.

Barnes, S. Barry, and David Edge (eds.). 1982. Science in context: readings in the sociology of science. Milton Keynes: Open University Press.

Bernasconi-Kohn, Lorenzo. 2006. How not to think about rules and rule-following: a response to Stueber. Philosophy of the Social Sciences, 36 (1): 86-94.

Bhaskar, Roy. 1986. Scientific realism and human emancipation. London: Verso.

Bhaskar, Roy. 1998 [1979]. The possibility of naturalism. London: Routledge.

Bloor, David. 1981. The strengths of the strong programme. Philosophy of the Social Sciences, 11 (2): 199-213.

Bloor, David. 1991 [1976]. Knowledge and social imagery. London and Boston: Routledge and Kegan Paul.

Bloor, David. 1992. Left and right Wittgensteinians. In Science as practice and culture, ed. Andrew Pickering. Chicago: University of Chicago Press, 266-282.

Bloor, David. 1997. Wittgenstein, rules and institutions. London and New York: Routledge.

Bloor, David. 1998. Changing axes: response to Mermin. Social Studies of Science, 28 (4): 624-635.

Bloor, David. 2004. Institutions and rule-scepticism: a reply to Martin Kusch. Social Studies of Science, 34 (4): 593-601.

Boyle, James. 1996. Shamans, software and spleens: law and the construction of the information society. Cambridge (MA) and London: Harvard University Press.

Boyle, James. 2003. The second enclosure movement and the construction of the public domain. Law and Contemporary Problems, 66 (1-2): 33-73.

Callon, Michel. 2002. Technology, politics and the market: an interview with Michel Callon, conducted by Andrew Barry and Donald Slater. Economy and Society, 31 (2): 285-306.

Callon, Michel, and Bruno Latour. 1992. Don't throw the baby out with the bath school: a reply to Collins and Yearley. In Science as practice and culture, ed. Andrew Pickering. Chicago: University of Chicago Press, 343-368.

Campbell, Eric, Brian Clarridge, Manjusha Gokhale, Lauren Birenbaum, Stephen Hilgartner, Neil Holtzman, David Blumenthal. 2002. Data withholding in academic genetics: evidence from a national survey. Journal of the American Medical Association, 287 (4): 473-480.

Collins, Harry M. 1983. The sociology of scientific knowledge: studies of contemporary science. Annual Review of Sociology, 9: 265-285. 
Collins, Harry M., and Trevor Pinch. 1993. The Golem: what everyone should know about science. Cambridge: Cambridge University Press.

Collins, Harry M., and Steven Yearley. 1992a. Epistemological chicken. In Science as practice and culture, ed. Andrew Pickering. Chicago: University of Chicago Press, 301-326.

Collins, Harry M., and Steven Yearley. 1992b. Journey into space. In Science as practice and culture, ed. Andrew Pickering. Chicago: University of Chicago Press: 369-389.

Eisenberg, Rebecca. 1987. Proprietary rights and the norms of science in biotechnology research. Yale Law Journal, 97 (2): 177-231.

Eisenberg, Rebecca. 1996. Public research and private development: patents and technology transfer in government-sponsored research. Virginia Law Review, 82 (8): 1663-1727.

Geiger, Roger. 2004. Knowledge and money. Stanford: Stanford University Press.

Greenberg, Daniel. 2001. Science, money and politics. Chicago: University of Chicago Press.

Hacking, Ian. 1992. Putting agency back into experiment. In Science as practice and culture, ed. Andrew Pickering. Chicago: University of Chicago Press, 29-64.

Haddock, Adrian. 2004. Re-thinking the 'strong programme' in the sociology of knowledge. Studies in the History of the Philosophy of Science Part A, 35 (1): 19-40.

Hands, D. Wade. 1994. The sociology of scientific knowledge: some thoughts on the possibilities. In New directions in economic methodology, ed. Roger Backhouse. London: Routledge, 75-106.

Hands, D. Wade. 1997. Conjectures and reputations: the sociology of scientific knowledge and the history of economic thought. History of Political Economy, 29 (4): 695-739.

Hands, D. Wade. 2001. Reflection without rules: economic methodology and contemporary science theory. Cambridge: Cambridge University Press.

Heller, Michael, and Rebecca Eisenberg. 1998. Can patents deter innovation? The anticommons in biomedical research. Science, 280 (5364): 698-701.

Hess, David. 1997. Science studies: an advanced introduction. New York and London: New York University Press.

Hesse, Mary. 1976. Truth and the growth of scientific knowledge. PSA: Proceedings of the Biennial Meeting of the Philosophy of Science Association: Symposia and Invited Papers, 2: 261-280.

Hesse, Mary. 1980. Revolutions and reconstructions in the philosophy of science. Bloomington (IN): Indiana University Press.

Hollis, Martin. 1982. The social destruction of reality. In Rationality and relativism, eds. Martin Hollis, and Steven Lukes. Oxford: Blackwell, 67-86.

King, Anthony. 1999a. The impossibility of naturalism: the antinomies of Bhaskar's realism. Journal for the Theory of Social Behaviour, 29 (3): 267-288.

King, Anthony. 1999b. Against structure: a critique of morphogenetic social theory. Sociological Review, 47 (2): 199-227.

King, Anthony. 2006. How not to structure a social theory: a reply to a critical response. Philosophy of the Social Sciences, 36 (4): 464-479.

Krimsky, Sheldon. 2003. Science in the private interest: has the lure of profits corrupted biomedical research? Lanham: Rowman and Littlefield.

Kripke, Saul. 1982. Wittgenstein: on rules and private language. Oxford: Blackwell. 
Kuhn, Thomas. 1970 [1962]. The structure of scientific revolutions. Chicago: Chicago University Press.

Kusch, Martin. 2004. Rule-scepticism and the sociology of scientific knowledge: the Bloor-Lynch debate revisited. Social Studies of Science, 34 (4): 571-591.

Kusch, Martin. 2006. A sceptical guide to meaning and rules: defending Kripke's Wittgenstein. Chesham: Acumen.

Lakatos, Imre. 1970. History of science and its rational reconstruction. Reprinted in The methodology of scientific research programmes: philosophical papers, vol. 1, eds. John Worrall, and Gregory Currie. Cambridge: Cambridge University Press, 102-138.

Laudan, Larry. 1977. Progress and its problems: towards a theory of scientific growth. London: Routledge and Kegan Paul.

Laudan, Larry. 1981. The pseudo-science of science? Philosophy of the Social Sciences, 11 (2): 173-198.

Laudan, Larry. 1982. More on Bloor. Philosophy of the Social Science, 12 (1): 71-74.

Laudan, Larry. 1998. De-mystifying underdetermination. In Philosophy of science: the central issues, eds. Martin Curd, and Jan A. Cover. New York and London: W. W. Norton \& Company, 320-353. Previously printed in [1990] Scientific theories, Minnesota Studies in the Philosophy of Science, vol. 14, ed. C. Wade Savage. Minneapolis (MN): University of Minnesota Press, 267-297.

Lynch, Michael. 1992a. Extending Wittgenstein: the pivotal move from epistemology to the sociology of science. In Science as practice and culture, ed. A. Pickering. Chicago: University of Chicago Press, 215-265.

Lynch, Michael. 1992b. From the "will to theory" to the discursive collage: a reply to Bloor's "Left and right Wittgensteinians". In Science as practice and culture, ed. Andrew Pickering. Chicago: University of Chicago Press, 283-299.

MacKenzie, Donald. 1981. Notes on the science and social relations debate. Capital and Class, 14: 47-60.

Mäki, Uskali. 1992. Social conditioning in economics. In Post-Popperian methodology of economics: recovering practice, ed. N. de Marchi. Boston: Kluwer, 65-104.

Mermin, N. David. 1998. The science of science: a physicist reads Barnes, Bloor and Henry. Social Studies of Science, 28 (4): 603-623.

Merton, Robert K. 1973. The sociology of science: theoretical and empirical investigations. Chicago: Chicago University Press.

Mirowski, Philip, and Esther-Mirjam Sent (eds.). 2002. Science bought and sold. Chicago: University of Chicago Press.

Mirowski, Philip, and Esther-Mirjam Sent. 2008. The commercialization of science and the response of STS. In New handbook of STS, eds. Edward Hackett, Judy Wacjman, Olga Amsterdamska, and Michael Lynch.Cambridge (MA): MIT Press, 635-689.

Nelson, Richard. 2001. Observations on the post-Bayh-Dole rise of patenting at American universities. Journal of Technology Transfer, 26 (1-2): 13-19.

Nelson, Richard. 2004. The market economy, and the scientific commons. Research Policy, 33 (3): 455-471.

Newfield, Christopher. 2003. Ivy and industry: business and the making of the American university, 1880-1980. Durham (NC) and London: Duke University Press. 
Pickering, Andrew. 1992. From science as knowledge to science as practice. In Science as practice and culture, ed. Andrew Pickering. Chicago: University of Chicago Press, 1-28.

Quine, Willard V. O. 1960. Word and object. Cambridge (MA): Harvard University Press.

Quine, Willard V. O. 1980 [1961]. From a logical point of view. Cambridge (MA) and London: Harvard University Press.

Resnik, David. 2007. The price of truth: how money affects the norms of science. Oxford: Oxford University Press.

Rosenberg, Alan. 1985. Methodology, theory and the philosophy of science. Pacific Philosophical Quarterly, 66 (4): 377-93.

Sent, Esther-Mirjam. 1999. Economics of science: survey and suggestions. Journal of Economic Methodology, 6 (1): 95-124.

Shapin, Steven. 1995. Here and everywhere: sociology of scientific knowledge. Annual Review of Sociology, 21: 289-321.

Shapin, Steven. 2003. Ivory tower. London Review of Books, 25 (17): 15-19.

Shapin, Steven, and Simon Shaffer. 1985. Leviathan and the air pump: Hobbes, Boyle, and the experimental life. Princeton: Princeton University Press.

Sharrock, Wesley. 2004. No case to answer: a response to Martin Kusch's 'Rulescepticism and the sociology of scientific knowledge'. Social Studies of Science, 34 (4): 603-614.

Stueber, Karsten. 2005. How to think about rules and rule-following. Philosophy of the Social Sciences, 35 (3): 307-323.

Stueber, Karsten. 2006. How to structure a social theory? A critical response to Anthony King's The structure of social theory. Philosophy of the Social Sciences, 36 (1): 95-104.

Suppe, Frederick. 1977 [1972]. The structure of scientific theories. Urbana (IL): University of Illinois Press.

Tijssen, Robert. 2004. Is the commercialisation of scientific research affecting the production of public knowledge? Global trends in the output of corporate research articles. Research Policy, 33 (5): 709-733.

Washburn, Jennifer. 2005. University Inc.: the corporate corruption of American higher education. New York: Basic Books.

Wittgenstein, Ludwig. 2001 [1953]. Philosophical investigations. Oxford: Blackwell.

Woolgar, Steve. 1992. Some remarks about positionism: a reply to Collins and Yearley. In Science as practice and culture, ed. Andrew Pickering. Chicago: University of Chicago Press, 327-342.

Worrall, John. 1990. Rationality, sociology and the symmetry thesis. International Studies in the Philosophy of Science, 4 (3): 305-319.

David Tyfield is a research associate at the Institute for Advanced Studies, Lancaster University. His research is on the (global) political economy and philosophy of science and innovation, with a particular focus on climate change and the life sciences.

Contact e-mail: <d.tyfield@lancaster.ac.uk> 